\title{
Recurrent Stroke/TIA in Cryptogenic Stroke Patients with Patent Foramen Ovale
}

\author{
Leanne Casaubon, Peter McLaughlin, Gary Webb, Erik Yeo, Darren Merker, \\ Cheryl Jaigobin
}

\begin{abstract}
Background: Patent foramen ovale (PFO) is present in $40 \%$ of patients with cryptogenic stroke and may be associated with paradoxical emboli to the brain. Therapeutic options include antiplatelet agents, anticoagulation, percutaneous device and surgical closure. We assessed the hypothesis that there are differences in rates of recurrent TIA or stroke between patients in the four treatment groups. Methods: Patients presenting from January 1997 with cryptogenic stroke or TIA and PFO were followed prospectively until June 2003. Treatment choice was made on an individual case basis. The primary outcome was recurrent stroke. The secondary outcome was a composite of stroke, TIA, and vascular death. Results: Baseline. Our cohort consisted of 121 patients; 64 (53\%) were men. Median age was 43 years. Sixty-nine percent presented with stroke and 31\% with TIA. One or more vascular risk factor was present in $40 \%$. Atrial septal aneurysm (ASA) was present in 24\%. Treatment consisted of antiplatelet agents (34\%), anticoagulation (17\%), device $(39 \%)$ and surgical closure $(11 \%)$. Follow-up. Recurrent events occurred in 16 patients (9 antiplatelet, 3 anticoagulation, 4 device closure); 7 were strokes, 9 were TIA. Comparing individual treatments there was a trend toward more strokes in the antiplatelet arm $(\mathrm{p}=0.072)$; a significant difference was seen for the composite endpoint $(\mathrm{p}=0.012)$. Comparing closure versus combined medical therapy groups, a significant difference was seen for primary $(\mathrm{p}=0.014)$ and secondary $(\mathrm{p}=0.008)$ outcomes, favoring closure. Age and pre-study event predicted outcome. Conclusion: Patent foramen ovale closure was associated with fewer recurrent events. Complications of surgical and device closure were self-limited.
\end{abstract}

RÉSUMÉ: L'accident vasculaire cérébral et l'accident ischémique transitoire chez les patients porteurs d'un foramen ovale perméable qui présentent un accident vasculaire cérébral cryptogénique. Contexte : Parmi les patients qui présentent un accident vasculaire cérébral (AVC) cryptogénique, $40 \%$ sont porteurs d'un foramen ovale perméable (FOP) qui peut être à l'origine d'une embolie paradoxale au cerveau. Les différentes options thérapeutiques sont : les antiplaquettaires, les anticoagulants, un dispositif percutané et la fermeture chirurgicale. Notre hypothèse était que le taux de récidive de l'accident ischémique transitoire (AIT) ou de l'AVC est différent selon que le patient reçoit l'un ou l'autre de ces traitements. Méthodes : Il s'agit d'une étude prospective de tous les patients porteurs d'un FOP ayant subi un AVC ou un AIT cryptogénique depuis janvier 1997 et qui ont été suivis jusqu'en juin 2003. Le choix du traitement était individualisé. Le critère d'évaluation principal était la récidive d'AVC. Le critère d'évaluation secondaire était composé de l'AVC, de l'AIT et du décès d'origine vasculaire. Résultats : Notre cohorte était constituée de 121 patients dont 64 étaient des hommes (53\%). L'âge médian était de 43 ans. Soixante-neuf pour cent ont consulté pour un AVC et $31 \%$ pour un AIT. Quarante pour cent avaient un ou plusieurs facteurs de risque vasculaires et $24 \%$ avaient un anévrisme septal auriculaire. Trente-quatre pour cent ont reçu des antiplaquettaires, $17 \%$ ont été anticoagulés, $39 \%$ ont reçu un dispositif percutané et $11 \%$ ont subi une occlusion chirurgicale. Au cours du suivi, 16 patients ont subi une récidive, soit un AVC chez 7 et un AIT chez 9. Neuf de ces patients étaient sous antiplaquettaires, 3 patients étaient anticoagulés et 4 patients avaient reçu un dispositif percutané. En comparant les quatre traitements, on note une tendance à observer plus d'AVC sous traitement antiplaquettaire $(p=0,072)$; la différence était significative pour le critère d'évaluation composé $(p=0,012)$. La différence entre la fermeture et les traitements médicaux était significative tant en ce qui concerne le critère d'évaluation principal $(\mathrm{p}=0,014)$ que le critère d'évaluation secondaire ( $\mathrm{p}=$ 0,008), en faveur de la fermeture. L'âge et l'événement précédant l'étude prédisait l'issue. Conclusion : Moins de récidives ont été observées chez les patients qui ont subi une occlusion du FOP. Les complications de la chirurgie et de l'implantation d'un dispositif percutané étaient autolimitées.

Can. J. Neurol. Sci. 2007; 34: 74-80

Patent foramen ovale (PFO) is well-described in $17 \%-35 \%$ of the population. ${ }^{1}$ However, there is a two to four-fold increase in prevalence in patients with cryptogenic stroke. ${ }^{2}$ While the true clinical significance of PFO in patients with cryptogenic stroke is unclear, this is attributed to paradoxical emboli from the venous system crossing to the left side of the heart to the cerebrovascular circulation. An association with prolonged immobility and Valsalva prior to stroke onset supports this mechanism, however, systemic deep venous thrombosis is found in only $10 \%$ of patients with stroke and PFO. ${ }^{3}$ Patent foramen ovale size, degree of shunting, and presence of atrial septal

\footnotetext{
From the University Health Network, Toronto General Hospital, Toronto, ON, Canada. ReCeived July 19, 2006. ACCEPTED IN FinAl FORM November 6, 2006. Reprint requests to: Cheryl Jaigobin, Toronto General Hospital, 200 Elizabeth Street, Toronto, Ontario, M5G 2C4, Canada.
} 
aneurysm (ASA) have been associated with increased risk of paradoxical embolism. ${ }^{4-7}$ A vulnerability of atrial conductivity and a propensity for paroxysmal atrial arrhythmias are postulated. ${ }^{8}$

Secondary prevention therapies for patients with stroke and PFO include antiplatelet agents, anticoagulation, percutaneous device closure and surgical closure. The long-term safety of percutaneous device closure is not known. Studies that have evaluated these therapies are limited by small sample sizes and patient heterogeneity; there is no consensus on optimal therapy.9. 14 We identified a cohort of patients with cryptogenic TIA or stroke and PFO treated at the University Health Network in Toronto, Canada. The cohort was followed prospectively to examine for recurrent vascular events and complications of treatment.

\section{Patients and Methods}

Patients presenting to the University Health Network Stroke Prevention Clinic between January 1997 and June 2003 with cryptogenic stroke or TIA and PFO were identified consecutively and followed prospectively until June 30, 2003. Patients were referred from Emergency Departments of three acute care hospitals comprising University Health Network, from inpatient units from these facilities, or from outside physicians. Patients with a known cardiac (with the exception of PFO/ASD), arterial or hematologic cause of stroke were excluded.

Demographic data were collected for each patient including age, gender, vascular risk factors and stroke history. Patent foramen ovale size, degree of right-to-left shunting at rest or with Valsalva maneuver, and associated ASA were recorded. A PFO was defined as a defect in the interatrial septum secundum and septum primum forming a flap allowing right-to-left shunting between atria as documented by colour flow Doppler. Shunting was defined by at least three micro-bubbles (created by agitating saline with air and injecting $10 \mathrm{cc}$ through a peripheral intravenous line) crossing from right to left atrium within three cardiac cycles on echocardiography. ${ }^{4}$ ASA was defined by displacement of the atrial septum $>10 \mathrm{~mm} .^{8}$

All patients had full neurologic and vascular assessments. Neuroimaging studies included brain CT or MRI. Vascular assessment consisted of arterial Doppler ultrasound and magnetic resonance angiography. All patients had a transthoracic echocardiogram followed by a transesophageal echocardiogram to confirm a PFO. Patients with right-to-left or bi-directional shunt at rest or with Valsalva were included in the study. A thrombophilia screen (for deficiencies of protein $\mathrm{C}$, protein $\mathrm{S}$, and antithrombin III, activated protein $\mathrm{C}$ resistance, MTHFR mutation, factor $\mathrm{V}$ Leiden, and prothrombin gene mutation) was performed if clinically indicated, in particular in patients $<45$ years old. All patients had a baseline ECG. If a suspicion of atrial arrhythmia (fibrillation or flutter) existed based on either the ECG or clinical history, 48-hour Holter monitoring was carried out.

Specific management for secondary stroke prevention was decided upon by the treating neurologist and patient after consideration of ease of treatment and anticipated compliance. Treatment options consisted of antiplatelet agents (acetylsalicylic acid $81 \mathrm{mg}$ or $325 \mathrm{mg}$, clopidogrel, or combination dipyridamole/acetylsalicylic acid), anticoagulation with warfarin (goal INR range 2.0-3.0), percutaneous device closure or surgical closure. The percutaneous devices used for closure were CardioSEAL and Amplatzer ASD Occluder; the decision regarding device type was made by the treating cardiologist. Patients with device closure were treated with anticoagulation for six months after the procedure and subsequently with aspirin indefinitely. Within six months of the device closure, patients were re-evaluated with TTE with agitated saline bubble study to evaluate for completeness of closure. Following surgical closure, patients were also treated with aspirin. Patients provided consent to be followed every six months with a structured phone interview to evaluate for outcome events. If an outcome event occurred, patients were seen in clinic to be re-evaluated.

The primary outcome was recurrent stroke. A secondary outcome measure was a composite of recurrent stroke, TIA, and death from vascular causes. TIA was defined as a focal neurological deficit with sudden onset resolving within less than 24 hours. Clinically, neurologic deficits lasting $>24$ hours were diagnosed as a stroke and were confirmed with CT or MRI. Vascular death included fatal ischemic stroke or intracranial hemorrhage, fatal myocardial infarction, cardiac arrest due to cardiovascular disease, or sudden death with no other cause defined. Patients were monitored for adverse events in each treatment group.

Statistical analysis was performed using S-PLUS for Statistics and SPSS version 13.0. Independent-samples t test for continuous variables and Chi-square analysis for categorical variables were used to compare baseline characteristics between treatment groups. Kaplan-Meier survival curves were constructed to evaluate event-free survival based on treatment group assignment. Univariable analysis for independent prognostic variables was carried out using a Cox proportional hazards model. For variables deemed significant in the

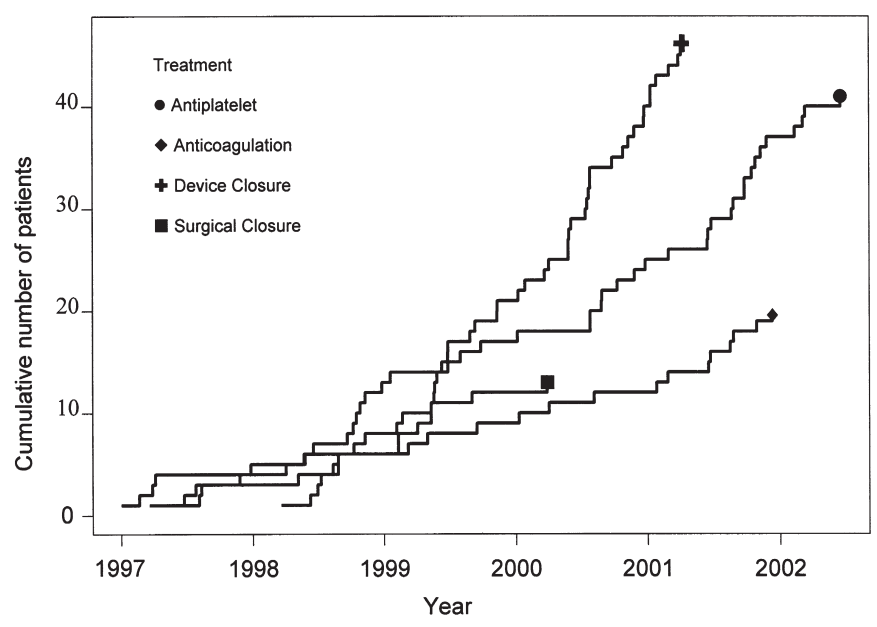

Figure 1: Enrollment over time in four treatment groups. 
Table 1: Baseline demographic characteristics of the cohort

\begin{tabular}{|c|c|c|c|c|c|c|}
\hline & \multicolumn{5}{|c|}{ Treatment } & \multirow[t]{2}{*}{ P-value* } \\
\hline & Total & $\begin{array}{l}\text { Anti- } \\
\text { platelet }\end{array}$ & $\begin{array}{c}\text { Anti- } \\
\text { coagulant }\end{array}$ & Device & Surgery & \\
\hline \multicolumn{5}{|l|}{ Subject numbers $(\%$} & $13(11)$ & \multirow{3}{*}{$0.02 * *$} \\
\hline Mean Age (years) & 46 & 51 & 49 & 43 & 39 & \\
\hline \multirow[t]{2}{*}{ Range } & $15-79$ & $21-79$ & $20-79$ & $15-73$ & $25-57$ & \\
\hline & $\mathrm{n}(\%)$ & $\mathrm{n}(\%)$ & $\mathrm{n}(\%)$ & $\mathrm{n}(\%)$ & $\mathrm{n}(\%)$ & \\
\hline \multicolumn{7}{|l|}{ Gender } \\
\hline Male & $64(53)$ & $22(54)$ & $11(55)$ & $25(53)$ & $6(46)$ & \multirow{2}{*}{0.97} \\
\hline Female & $57(47)$ & $19(46)$ & $9(45)$ & $22(47)$ & $7(54)$ & \\
\hline \multicolumn{7}{|l|}{ Vascular risk factors } \\
\hline Hypertension & $20(17)$ & $12(29)$ & $3(15)$ & $3(6)$ & $2(15)$ & 0.03 \\
\hline Diabetes & $7(6)$ & $3(7)$ & $1(5)$ & $2(4)$ & $1(8)$ & 0.89 \\
\hline Hyperlipidemia & $28(23)$ & $13(32)$ & $5(25)$ & $8(17)$ & $2(15)$ & 0.39 \\
\hline \multicolumn{7}{|l|}{ Smoking status } \\
\hline Current & $18(15)$ & $9(22)$ & $2(10)$ & $5(11)$ & $2(15)$ & \multirow{2}{*}{0.74} \\
\hline Previous & $26(21)$ & $10(24)$ & $4(20)$ & $9(19)$ & $3(23)$ & \\
\hline \multicolumn{7}{|l|}{ Baseline event } \\
\hline TIA & $38(31)$ & $19(46)$ & $4(20)$ & $13(28)$ & $2(15)$ & \multirow{2}{*}{0.07} \\
\hline Stroke & $83(69)$ & $22(54)$ & $16(80)$ & $34(72)$ & $11(85)$ & \\
\hline Pre-study stroke/TIA & $11(9)$ & $5(12)$ & $4(20)$ & $1(2)$ & $1(8)$ & 0.06 \\
\hline Atrial septal aneurysm ${ }^{\dagger}$ & $28(24)$ & $3(7)$ & $7(35)$ & $14(32)$ & $4(31)$ & 0.01 \\
\hline Atrial septal defect ${ }^{\ddagger}$ & $7(6)$ & $2(5)$ & $1(5)$ & $3(7)$ & $1(8)$ & 1.00 \\
\hline
\end{tabular}

*Fisher's exact test for associations between treatment and baseline variables; **Test performed with age treated categorically - see text; †ASA missing data for 3 patients; $\$$ ASD missing data for 1 patient.

univariable analysis, multivariable Cox models were constructed.

Approval for this study was obtained from the Research Ethics Board at our institution.

\section{RESULTS}

Our cohort consisted of 121 patients. Recruitment was steady throughout the study, with two treatment phases noted. While the use of antiplatelet agents and anticoagulation remained stable during the study, surgical closure was used in the earlier phase between 1997-2000 and was replaced by percutaneous device closure after January 2001 as expertise with this procedure developed (Figure 1). Baseline demographics for our cohort are shown in Table 1. There were similar proportions of men and women within the four treatment groups $(\mathrm{p}=0.97)$. The median age at baseline was 43 years. Few differences existed in baseline variables between the four groups. However, more patients with hypertension were treated with antiplatelet therapy $(\mathrm{p}=0.03)$ and more patients with ASA were treated with device closure $(\mathrm{p}=0.01)$. The baseline event was stroke in $83(69 \%)$ and TIA in $38(31 \%)$ patients; $9 \%$ had a pre-study event. Though a higher number of patients $(46 \%)$ in the antiplatelet group had an index TIA event, there was no difference in baseline events among treatment groups $(\mathrm{p}=0.07)$. One or more vascular risk factor was present in $40 \%$ of patients. All patients had a negative hypercoagulable screen. Fifty patients had septal defect measurements taken and $33(66 \%)$ were $<5 \mathrm{~mm}, 16(32 \%)$ were $5-10 \mathrm{~mm}$, and $1(2 \%)$ was $>10 \mathrm{~mm}$ diameter. Thirty-one patients (24\%) had an ASA with PFO.

Follow-up data was collected for all 121 patients. Median follow-up was 32 months; $40 \%$ had follow-up longer than 36 months. Data were censored on June 30, 2003 for 105 patients with no recurrent event. Recurrent events occurred in 16 patients (9 antiplatelet, 3 anticoagulation, 4 device closure and 0 surgical 


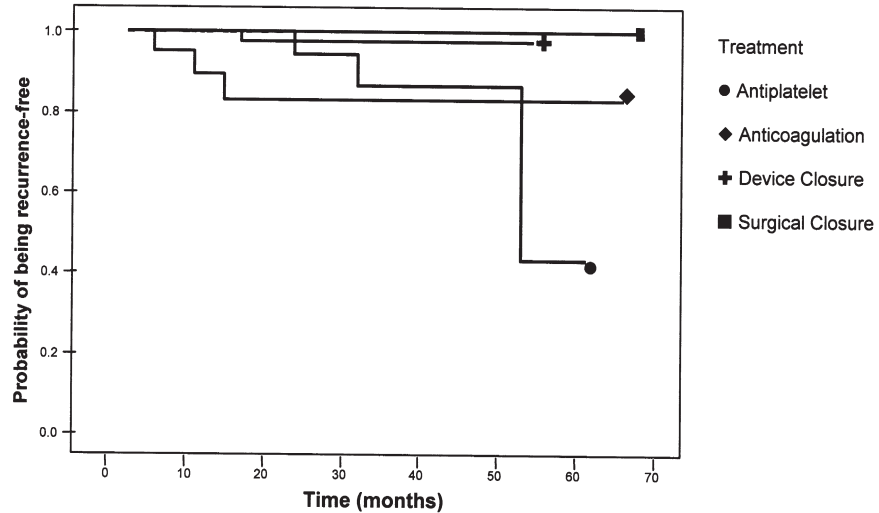

Figure 2: Kaplan-Meier analysis showing stroke-free survival in the four treatment groups.

closure); 7 recurrent events were stroke (3 antiplatelet, 3 anticoagulation, 1 device closure) and 9 were TIA (6 antiplatelet, 3 device). Recurrent events were reinvestigated and no new etiology was identified. One patient became disabled from a recurrent stroke (modified Rankin score 4). Two deaths occurred from non-vascular causes (one prostate cancer, one gynecologic cancer).

Kaplan-Meier survival analysis for the primary outcome measure using the four treatment groups showed a trend toward more recurrent strokes in the antiplatelet arm $(\mathrm{p}=0.072)$ (Figure 2). Comparing PFO closure (device and surgical groups combined) to combined medical therapy groups revealed fewer recurrent strokes after closure $(p=0.014)$ (Figure 3). For the composite endpoint of stroke, TIA, and vascular death, a difference was seen between the four treatment groups $(\mathrm{p}=0.012)$ in the survival analysis and in comparing closure to medical therapy $(\mathrm{p}=0.008)$, again favoring PFO closure. Univariable Cox proportional hazards models identified age $(\mathrm{p}=0.03)$, pre-study event $(p=0.02)$, and treatment $(p=0.01)$ to be predictors of outcome (Table 2). To evaluate for interactions between these variables, multivariable Cox models were constructed. Pre-study event $(p=0.016)$ remained significant but age $(p=0.103)$ and treatment $(\mathrm{p}=0.115)$ lost significance.

In the device group all but one patient received a CardioSEAL device. Complications of PFO device closure included post-procedure arrhythmia (8 patients), chest pain (3 patients) and groin hematoma (1 patient). Two patients with device closure developed thrombus on the device and subsequently underwent surgical closure without further complications; these patients did not adhere to post-procedural antithrombotic therapy (both remained in the device closure group for analysis). Five patients had incomplete closure; two of five had recurrent TIA, one with a CardioSEAL device and the other with an Amplatzer ASD Occluder. In the surgical closure group, one patient developed self-limiting post-operative pericarditis. There were no bleeding complications associated with antiplatelet or anticoagulant therapy.

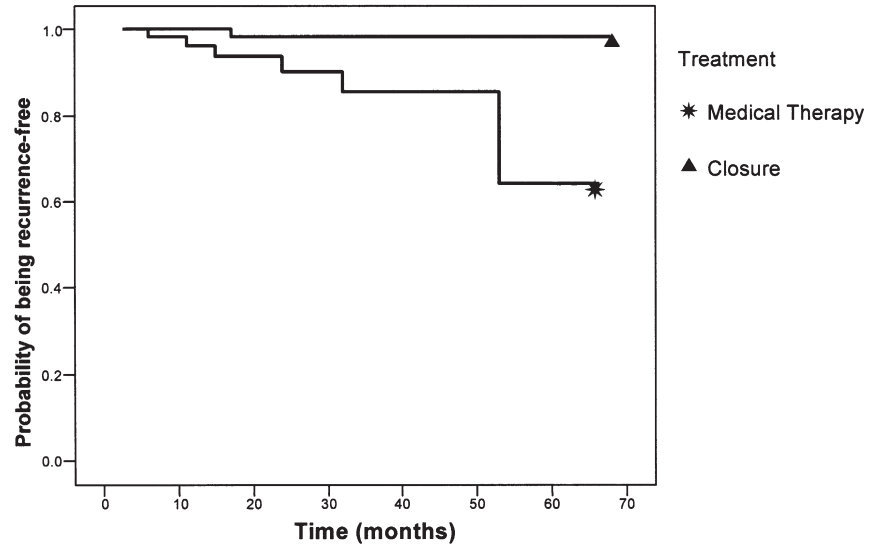

Figure 3: Kaplan-Meier analysis showing stroke-free survival of combined medical therapy groups versus closure.

\section{DISCUSSION}

This study provides insight into the current care practices for patients with cryptogenic stroke and PFO, based on care at a large acute care hospital in Ontario. This cohort was a young homogeneous group with modest degree of atherosclerotic risk factors and no other stroke etiology. Of the four available treatments during the study, surgical closure was replaced by device closure as the main technique for PFO closure over time. Patent foramen ovale closure was used typically in younger patients and in those with ASA. Antiplatelet therapy was more commonly used in older patients.

We observed 16 recurrent stroke/TIA events over a mean follow-up of 32 months. This is comparable to other published reports. Harrer et al reported 11 recurrent events in a cohort of 124 patients followed over a mean period of 52 months. ${ }^{15}$ Fewer outcome events were seen in patients with PFO closure. Between the four treatment groups, there was a trend toward more recurrent strokes in the antiplatelet group. Comparison of the combined device and surgical closure groups to combined medical therapy demonstrated a lower number of outcome events in favor of closure. Several studies have looked at PFO closure, with few comparisons of closure and medical therapy. ${ }^{11-14}$ Windecker et al ${ }^{16}$ evaluated 308 patients who had either medical therapy or percutaneous device closure. For the endpoint of TIA or stroke, a non-significant difference was seen between all patients with attempted device closure versus medical therapy; in the subgroup of patients with complete closure (83\%), there was a significant benefit compared to medical therapy $(6.5 \%$ vs. $22.2 \%, \mathrm{p}=0.04)$. Harrer et $\mathrm{al}^{15}$ reported no difference in recurrent events between patients treated with percutaneous device closure and medical therapy. Incomplete PFO closure has been reported in up to $20 \%$ of patients after percutaneous device closure and is shown to predict recurrence of cerebrovascular events. ${ }^{15-19}$ Two of five patients with recurrent TIA in our percutaneous device closure group had incomplete closure, possibly reducing the preventive effect of closure. 
Table 2: Univariable Cox regression analysis results for predictor variables

\begin{tabular}{lrrrr}
\hline \multicolumn{1}{c}{ Variable } & Coefficient* & $\begin{array}{c}\text { Hazard } \\
\text { Ratio }\end{array}$ & $\begin{array}{c}\text { 95\% Confidence } \\
\text { Interval** }\end{array}$ & P-Value+ \\
\hline \hline Age (mid-quartile) & 0.035 & & & \\
$\quad$ 30 years & & 1.00 & $1.00-1.00$ & \\
39 years & & 1.37 & $1.02-1.83$ & 0.03 \\
51 years & & 2.08 & $1.05-4.11$ & \\
$\quad$ 67 years & 0.012 & 3.64 & $1.09-12.08$ & \\
Gender - female & 0.11 & 1.01 & $0.38-2.70$ & 0.98 \\
Hypertension & 0.804 & 2.24 & $0.32-3.92$ & 0.87 \\
Diabetes & 0.087 & 1.09 & $0.31-9.86$ & 0.33 \\
Hyperlipidemia & & & & 0.88 \\
Smoking status & -0.034 & 1.00 & $1.00-1.00$ & 0.48 \\
$\quad$ Previous & 0.741 & 2.17 & $0.48-9.83$ & \\
$\quad$ Current & -0.409 & 1.51 & $0.54-4.18$ & 0.44 \\
Baseline event - TIA & 1.62 & 5.03 & $1.60-15.78$ & 0.02 \\
Pre-study event & -1.62 & 5.05 & $0.67-38.24$ & 0.046 \\
ASA - not present & & & & \\
Treatment & --- & 1.00 & $1.00-1.00$ & \\
$\quad$ Antiplatelet & -0.527 & 0.59 & $0.16-2.19$ & 0.012 \\
$\quad$ Anticoagulant & -1.272 & 0.28 & $0.09-0.92$ & 0.012 \\
$\quad$ Device & -8.198 & N/A & N/A & \\
$\quad$ Surgery & &
\end{tabular}

*Estimated coefficients for Cox modelling; Negative coefficients indicate correlation of a variable with fewer outcome events; ** 95\% confidence intervals based on Wald estimates of standard errors; $\dagger$ Likelihood ratio P-values; N/A - not applicable.

Factors associated with outcome in our cohort include increasing age, pre-study event, and treatment. Older patients were treated more often with antiplatelet therapy in our study and as such, age may be associated with the increase in recurrent events in this treatment group. The relationship between PFO and stroke is stronger in studies with a younger patient population. Studies evaluating patients under age 60 have reported a clear association between $\mathrm{PFO}$ and/or ASA and initial cryptogenic stroke $\mathrm{e}^{20,21}$ as well as recurrent stroke events. ${ }^{22-24} \mathrm{~A}$ meta-analysis by Overell et $\mathrm{al}^{25}$ confirmed the association between PFO and/or ASA and first ischemic stroke in the age category of $<55$ years of age with a two-fold increased incidence of these cardiac defects compared with older patients. Conversely, the PICSS trial, a study of older patients and patients with other causes of stroke, did not identify differences in rates of recurrent TIA or stroke in patients with or without PFO, ${ }^{9,26}$

Baseline event was not a predictor of recurrent events. Patients with TIA generally have a higher risk for recurrent vascular events. ${ }^{27}$ However, in our patients with cryptogenic
TIA it is not clear that the risk of recurrent vascular events is higher than in cryptogenic stroke, as those TIA patients with the highest risk of recurrence (due to significant carotid atherosclerotic disease and cardioembolic stroke related to atrial fibrillation) were excluded from this study. Although there was a larger number of patients with an index TIA in the antiplatelet group, there is no clear evidence that this affected the recurrence rate. Another factor, the presence of ASA, has been associated with increased risk of recurrent stroke. ${ }^{23}$ ASA was present in $24 \%$ of our patients, consistent with previous reports. ${ }^{20,23,28}$ However, the association with ASA and increased recurrent stroke was not found in our study. This may be attributed to our cohort size and unequal distribution in the treatment groups since one-half of patients with ASA were treated with device closure. Patent foramen ovale size was not related to an increased risk of recurrent ischemic events in our study. However, all patients did not have full measurements of diameter; of the 50 patients with measurements, the majority $(66 \%)$ were small, $<5 \mathrm{~mm}$ in diameter. Previous published data on PFO size and recurrent 
stroke have demonstrated an increased risk with larger PFO size; several studies showing a greater risk with PFO sizes $>4 \mathrm{~mm}$ in diameter. ${ }^{6,9}$

The main limitation of our study was that treatments were not evaluated in a randomized fashion. As such, differences in certain baseline characteristics between treatment groups were seen. Associations between factors including age and treatment in predicting outcome were found; thus our results must be interpreted with caution. Also, the number of patients in each treatment group was relatively small and there were few outcome events. Our study did not have a control group of cryptogenic stroke patients without PFO and we did not compare rates of recurrent stroke or TIA in patients with and without PFO. Thus, we were unable to evaluate PFO as an independent predictor of recurrent stroke.

Currently, treatment decisions for stroke prevention in patients with PFO are influenced by many factors including age, thrombophilia, family history of stroke, PFO size, degree and direction of shunting, and association with ASA. ${ }^{29}$ A practice parameter was published in 2004, concluding that PFO conferred no increased risk of recurrent stroke or death in medically treated patients (RR 0.95; CI 0.62 to 1.44) and that insufficient evidence existed to make any conclusions regarding percutaneous device or surgical closure. ${ }^{30}$

We report that PFO closure was associated with fewer recurrent vascular events compared to medical therapy in our cohort. Patent foramen ovale closure with percutaneous device had self-limiting complications and no deaths and may be considered a safe potential therapy. Patients treated with antiplatelet therapy showed a higher risk of recurrent ischemic events, though age may have contributed to this finding. Further studies to evaluate the difference in outcomes with medical therapy versus PFO closure in a randomized manner are now underway to better elucidate optimal therapy for secondary stroke prevention in this group of patients.

\section{FUNDING}

Funding support was provided by the Krembil Neuroscience Grant through the University Health Network.

\section{ACKNOWLEDGEMENTS}

The authors thank Ms. Marguerite Ennis for her statistical support.

\section{DisClosures}

Dr. Jaigobin is currently a PI in the CLOSURE 1 trial sponsored by NMT that commenced enrollment in Toronto Feb 2005. It is important to note that all of the data for the submitted study was obtained prior to participation in the trial. In addition, funding provided will cover costs of the trial.

The other authors have no conflicts of interest.

\section{REFERENCES}

1. Hagen PT, Scholz DG, Edwards WD. Incidence and size of patent foramen ovale during the first 10 decades of life: an autopsy study of 965 normal hearts. Mayo Clin Proc. 1984;59:17-20.

2. Lechat PH, Mas JL, Lascault G, Loran P, Theard M, Klimczac M, et al. Prevalence of patient foramen ovale in patients with stroke. N Engl J Med. 1988;318:1148-52.
3. Lethen H, Flachskampf FA, Schneider R, Sliwka U, Kohn G, Noth $\mathrm{J}$, et al. Frequency of deep vein thrombosis in patients with patent foramen ovale and ischemic stroke or transient ischemic attack. Am J Cardiol. 1997;80:1066-9.

4. De Castro S, Cartoni D, Fiorelli M, Rasura M, Anzini A, Zanette EM, et al. Morphological and functional characteristics of patent foramen ovale and their embolic implications. Stroke. 2000;31:2407-13.

5. Hanna JP, Sun JP, Furlan AJ, Stewart WJ, Sila CA, Tan M. Patent foramen ovale and brain infarct: echocardiographic predictors, recurrence, and prevention. Stroke. 1994;25:782-6.

6. Steiner MM, Di Tullio MR, Rundek T, Gan R, Chen X, Liguori C, et al. Patent foramen ovale size and embolic brain imaging findings among patients with ischemic stroke. Stroke. 1998;29:944-8.

7. Stone DA, Godard J, Corretti MC, Kittner SJ, Sample C, Price TR, et al. Patent foramen ovale: association between the degree of shunting by contrast transesophageal echocardiography and the risk of future ischemic neurologic events. Am Heart J. 1996;131:158-61.

8. Berthet K, Lavergne T, Cohen A, Guize L, Bousser M-G, Le Heuzey J-Y, et al. Significant association of atrial vulnerability with atrial septal abnormalities in young patients with ischemic stroke of unknown cause. Stroke. 2000;31:398-403.

9. Homma S, Sacco RL, Di Tullio MR, Sciacca RR, Mohr JP, for the PFO in Cryptogenic Stroke Study (PICSS) Investigators. Effect of medical treatment in stroke patients with patent foramen ovale: Patent foramen ovale in cryptogenic stroke study. Circulation. 2002;105:2625-31.

10. Nendaz MR, Sarasin FP, Junod AF, Bogousslavsky J. Preventing stroke recurrence in patients with patent foramen ovale: antithrombotic therapy, foramen closure, or therapeutic abstention? A decision analytic perspective. Am Heart J. 1998;135:532-41.

11. Ende DJ, Chopra PS, Rao PS. Transcatheter closure of atrial septal defect or patent foramen ovale with the buttoned device for prevention of recurrence of paradoxical embolism. Am J Cardiol. 1996;78:233-6.

12. Guffi M, Bogousslavsky J, Jeanrenaud X, Devuyst G, Sadeghi H. Surgical prophylaxis of recurrent stroke in patients with patent foramen ovale: a pilot study. J Thorac Cardiovasc Surg. 1996;112:260-3.

13. Ruchat P, Bogousslavsky J, Hurni M, Fischer AP, Jeanrenaud X, von Segesser LK. Systematic surgical closure of patent foramen ovale in selected patients with cerebrovascular events due to paradoxical embolism. Early results of a preliminary study. Eur J Cardiothorac Surg. 1997;11:824-7.

14. Windecker S, Wahl A, Chatterjee T, Garachemani A, Eberli FR, Seiler C, et al. Percutaneous closure of patent foramen ovale in patients with paradoxical embolism: long-term risk of recurrent thromboembolic events. Circulation. 2000;101:893-8.

15. Harrer JU, Wessels T, Franke A, Lucas S, Berlit P, Klotzsch C. Stroke recurrence and its prevention in patients with patent foramen ovale. Can J Neurol Sci. 2006;33:39-47.

16. Windecker S, Wahl A, Nedeltchev K, Arnold M, Schwerzmann M, Seiler C, et al. Comparison of medical treatment with percutaneous closure of patent foramen ovale in patients with cryptogenic stroke. J Am Coll Cardiol. 2004;44(4):750-61.

17. Wahl A, Meier B, Haxel B, Nedeltchev K, Arnold M, Eicher E, et al. Prognosis after percutaneous closure of patent foramen ovale for paradoxical embolism. Neurology. 2001;57:1330-2.

18. Braun MU, Fassbender D, Schoen SP, Haass M, Schraeder R, Scholtz W, et al. Transcatheter closure of patent foramen ovale in patients with cerebral ischemia. J Am Coll Cardiol. 2002;39(12):2019-25.

19. Bruch L, Parsi A, Grad MO, Rux S, Burmeister T, Krebs H, et al. Transcatheter closure of interatrial communications for secondary prevention of paradoxical embolism: single-center experience. Circulation. 2002;105(24):2845-8.

20. Bogousslavsky J, Garazi S, Jeanrenaud X, Aebischer N, Van Melle G, for the Lausanne Stroke with Paradoxical Embolism Study Group. Stroke recurrence in patients with patent foramen ovale: The Lausanne Study. Neurology. 1996;46(5):1301-5. 
21. Cabanes L, Mas JL, Cohen A, Amarenco P, Cabanes PA, Oubary P, et al. Atrial septal aneurysm and patent foramen ovale as risk factors for cryptogenic stroke in patients less than 55 years of age. A study using transesophageal echocardiography. Stroke. 1993;24(12):1865-73.

22. Mas JL, Zuber M. Recurrent cerebrovascular events in patients with patent foramen ovale, atrial septal aneurysm, or both and cryptogenic stroke or transient ischemic attack. French Study Group on Patent Foramen Ovale and Atrial Septal Aneurysm. Am Heart J. 1995;130:1083-8.

23. Mas JL, Arquizan C, Lamy C, Zuber M, Cabanes L, Derumeaux G, et al. Recurrent cerebrovascular events associated with patent foramen ovale, atrial septal aneurysm or both. N Engl J Med. 2001;345:1740-6.

24. Nedeltchev K, Arnold M, Wahl A, Sturzenegger M, Vella EE, Windecker S, et al. Outcome of patients with cryptogenic stroke and patent foramen ovale. J Neurol Neurosurg Psychiatry. 2002:72:347-50.

25. Overell JR, Bone I, Lees KR. Interatrial septal abnormalities and stroke: a meta-analysis of case-control studies. Neurology. 2000;55(8):1172-9.
26. Adams HP Jr, Bendixen B, Kappelle LJ, Biller K, Love BB, Gordon DL, et al. Classification of subtype of acute ischemic stroke: definitions for use in a multicenter clinical trial. Stroke. 1993;24(1):35-41.

27. Gladstone D, Kapral MK, Fang J, Laupacis A, Tu JV. Management and outcomes of transient ischemic attacks in Ontario. Can Med Assoc J. 2004;170(7):1099-104.

28. Mattioli AV, Aquilina M, Oldani A, Longhini C, Mattioli G. Atrial septal aneurysm as a cardioembolic source in adult patients with stroke and normal carotid arteries. Eur Heart J. 2001;22:261-8.

29. Rodriguez CJ, Homma S. Patent foramen ovale and stroke. Curr Treatment Options in Cardiovasc Med. 2003;5:233-40.

30. Messe SR, Silverman ID, Kizer JR, Homma S, Zahn C, Gronseth G, et al. Practice parameter: recurrent stroke with patent foramen ovale and atrial septal aneurysm. Report of the Quality Standards Subcommittee of the American Academy of Neurology. Neurology. 2004;62:1042-50. 